\title{
ANTROPOLOGÍA
}

\section{ACTITUDES DE GÉNERO Y ESTEREOTIPOS EN ENFERMERÍA}

\author{
$M^{\mathrm{a}}$ Dolores Burguete Ramos ${ }^{1}$, José Ramón Martínez Riera², \\ Germán Martín González ${ }^{3}$
}

${ }^{1}$ Enfermera. Lic. Antropología. Profesora Universidad Católica de Valencia

${ }^{2}$ Enfermero. Doctor Enfermería. Profesor Departamento Enfermería Comunitaria,

Med. Preventiva y salud Pública e $H^{a}$ de la Ciencia. Universidad de Alicante

${ }^{3}$ Doctor en Matemáticas. Profesor Universidad Católica de Valencia

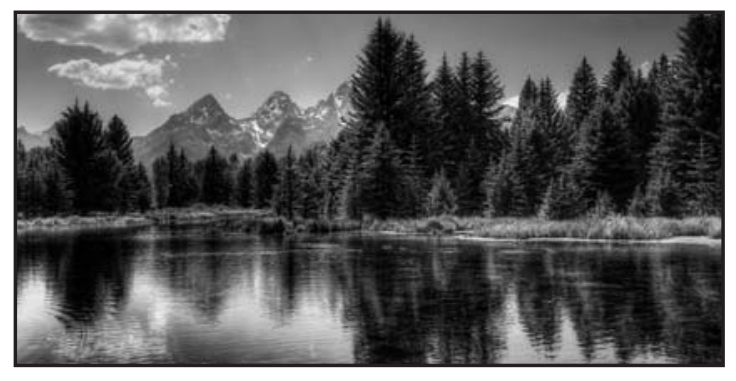

\section{GENDER ATTITUDES AND STEREOTYPES IN NURSING}

\section{SUMMARY}

Introduction: In 1993, Annette M. Links, conducted the study on gender attitudes and stereotypes in nursing.

Objectives: To describe attitudes of nursing students to stereotypes of the nurse. To evaluate the evolution of perception of gender stereotypes of nursing students.

Subjects and methods: Observational, descriptive and diachronic. Structured survey was conducted 440 freshmen. At the end of third year, she passed the same questionnaire to 307 students.

The data were entered into a database in Xbase format and used the program SPSS 15.0. It has been used $t$ test. For the means for schools, ANOVA test was used. Significance level $>0.05$.

Results: Agreement in which women are more affectionate than men. Women are seen as more caring $(\mathrm{P}=0.011)$, less independent $(\mathrm{P}=0.000)$, less intelligent $(\mathrm{P}=0.011)$, less leadership $(\mathrm{P}=$ $0.000)$ and less possibility of promotion $(\mathrm{P}=$
$0.015)$. The men consider sex objects young nurses $(\mathrm{P}=0.029)$ and bossy older $(\mathrm{P}=0.018)$.

Conclusions: The results suggest evidence of the persistence of images of nurses in accordance with female stereotypes: Gender makes a difference in the surveyed population.

Key words: gender stereotypes, nursing students.

\section{ATITUDES DE GÊNERO E ESTEREÓTIPOS EM ENFERMAGEM}

\section{RESUMO}

Introdução: Em 1993, Annette M. Links realizou um estudo sobre atitudes de gênero e estereótipos em enfermagem.

Objetivos: Descrever atitudes de estudantes de Enfermagem frente a estereótipos da enfermeira. Valorar a evolução de estereótipos de gênero de enfermagem dos estudantes.

Sujetos e método: Estudo observacional, descritivo e diacrônico. Realizou-se entrevista estruturada com 440 alunos do primeiro curso. Ao finalizar o terceiro curso, foi realizado outro questionário igual com 307 alunos. Os achados foram lançados em uma base de dados em formato $\mathrm{X}$ base e foi utilizado o programa SPSS 15.0. Utilizou-se a teste t. Para as médias por escolas, se utilizou o teste ANOVA e o nível de significação $>0.05$.

Resultados: Os dados mostram que as mulheres são mais carinhosas que os homens. Elas se consideram mais carinhosas $(\mathrm{P}=0,011)$, menos indepen- 
dentes $(\mathrm{P}=0,000)$, menos inteligentes $(\mathrm{P}=0,011)$, com menor liderança $(\mathrm{P}=0,000)$ e menor possibilidade de promoção $(\mathrm{P}=0,015)$. Os homens consideram que as enfermeiras jovens representam objetos sexuais $(\mathrm{P}=0,029)$ e as idosas_são autoritárias $(\mathrm{P}=0,018)$.

Conclusões: Os resultados evidenciam a persistência de imagens de enfermeiras de acordo com os estereótipos femininos: o sexo marca diferenças na população entrevista.

Palavras chave: gênero, estereótipos, enfermagem, estudantes.

\section{RESUMEN}

Introducción: En 1993 Annette M. Links, realizó estudio sobre actitudes de género y estereotipos en enfermería.

Objetivos: Describir actitudes de estudiantes Enfermería ante estereotipos de la enfermera. Valorar la evolución de percepción de estereotipos de género de enfermería de los estudiantes.

Sujetos y método: Estudio observacional, descriptivo y diacrónico. Se realizó encuesta estructurada 440 alumnos de primer curso. Al finalizar tercer curso se volvió a pasar igual cuestionario a 307 alumnos.

Los datos se introdujeron en una base de datos en formato Xbase y se utilizó el programa SPSS 15.0. Se ha usado la prueba t.. Para las medias por escuelas, se ha usado la prueba ANOVA. Nivel de significación $>0.05$.

Resultados: Acuerdo en que las mujeres son más cariñosas que los hombres. Las mujeres se consideran más cariñosas $(\mathrm{P}=0,011)$, menos independientes $(\mathrm{P}=0,000)$, menos inteligentes $(\mathrm{P}=0,011)$, menor liderazgo $(\mathrm{P}=0,000)$ y menor posibilidad de promoción $(\mathrm{P}=0,015)$. Los varones consideran a las enfermeras jóvenes objetos sexuales $(\mathrm{P}=0,029)$ y a las mayores mandonas $(\mathrm{P}=0,018)$.

Conclusiones: Los resultados sugieren evidencia de la persistencia de imágenes de enfermeras de acuerdo con los estereotipos femeninos: El sexo marca diferencias en la población encuestada.

Palabras Clave: género, estereotipos, enfermería, estudiantes.

\section{INTRODUCCIÓN}

El género es la construcción cultural que asigna, jerárquicamente, en las esferas públicas y privadas, diferentes formas de comportamiento y roles a las mujeres y a los hombres sobre la base de su diferenciación sexual. Son por lo tanto una serie de atributos y funciones, que van más allá de lo biológico reproductivo, que han sido construidos social y culturalmente y que son adjudicados a los sexos para justificar diferencias y relaciones entre los mismos. El género es flexible y varía con los factores culturales, sociales, políticos y económicos.

En ocasiones sexo y género son confundidos con frecuencia. Se entiende sexo, la condición biológica con la que se nace, es decir nacemos hombre o mujer dependiendo de nuestra anatomía, por el contrarío el género como decíamos anteriormente es un producto cultural, ya que se definen por comportamientos atribuibles a los hombres o a las mujeres construidos socialmente y que carecen de una base biológica

Según el Diccionario de la Real Academia Española (RAE) un estereotipo es una Imagen o idea aceptada comúnmente por un grupo o sociedad con carácter inmutable. Es una imagen mental muy simplificada y con pocos detalles acerca de un grupo de gente que comparte ciertas cualidades características (o estereotípicas) y habilidades. El término se usa a menudo en un sentido negativo, considerándose que los estereotipos son creencias ilógicas que sólo se pueden cambiar mediante la educación. Es una representación repetida frecuentemente que convierte algo complejo en algo simple. Es un modo de categorizar el mundo real, de darle significado a un aspecto específico de ese mundo en vez de otro.

El estereotipo nos permite organizar información sobre el mundo.

Estos se convierten en un modo "natural" de pensar, de hablar y de bromear acerca de grupos sociales reales como las mujeres, los aborígenes, los inmigrantes, etc.

El estereotipo es un concepto de "grupo". Es algo que comparte un grupo y hay mucha uniformidad sobre su contenido. No existen los estereotipos "privados" y suelen estar basados en lo subjetivo. Su fuerza reside con el grado que es percibido por quienes los creen como una representa- 
ción válida de lo real.

Los estereotipos de género son propios de cada sociedad y cada cultura establece lo que se supone "natural" para cada sexo, definiendo lo que es "femenino" y "masculino".

Los estereotipos de género, son transmitidos y perpetuados en la familia, la escuela, los medios de comunicación, etc. Esta socialización se encarga de crear una identidad de género, de fomentar determinadas y diferentes formas de pensar, sentir y actuar entre los sexos, que sienta las bases para el desequilibrio del poder que se plantea y se trasmite a la esfera privada.

El rol es el conjunto de comportamientos y actitudes esperadas de una determinada persona o personas dentro de un esquema organizativo o un puesto específico dentro de una organización (Mompart 1994).

El rol de género masculino o femenino asigna funciones, actitudes, capacidades y limitaciones diferenciadas a mujeres y hombres, que la normativa de la cultura vigente establece como atributos "naturales" de ambos sexos. Son las tareas y actividades que una cultura asigna a los sexos. Los roles de género y la estratificación han variado muy ampliamente a través de la cultura y de la historia.

Todas las personas intentan ser congruentes con lo que el grupo social espera de ellas y los estereotipos de género se construyen a partir de esta premisa.

Levi-Strauss (1961), nos ha ayudado a comprender porque se asignan valores distintos a muchas de las acciones relacionadas con las mujeres y con los hombres y por lo tanto el enfoque de género nos permite conocer las razones por las cuales se adjudica una determinada imagen y se reproduce una y otra vez en la sociedad en algunas profesiones o roles profesionales.

Socialmente se acepta en mayor o menor medida que las mujeres están hechas para los cuidados en todas sus variantes, algo que pertenece a la esfera privada y que los hombres están más preparados para las actividades relacionadas con la esfera pública, aquellas que confieren más prestigio o poder.

Por lo tanto podríamos definir a grandes rasgos el estereotipo femenino que nos presentan las revistas y programas televisivos como la imagen de una mujer buena, tierna, amable, comprensiva, atractiva físicamente, afectiva y preocupada siempre por los demás.

En cuanto al estereotipo masculino, como agresivo, triunfador, sustento de la familia, activo, independiente, profesional.

Estas creencias estereotipadas contribuyen o pueden hacerlo a definir que actividades se consideran más apropiadas para unos y para otras (CEP 2005).

\section{Estereotipos y Enfermería}

La Enfermería, ha estado influida por las consideraciones de género al ser una actividad eminentemente femenina. Esto ha condicionado su evolución y desarrollo, dando lugar a una profesión a la que le esta costando mucho alcanzar las metas previstas. En la actualidad, en que teóricamente deberíamos haber superado los roles sexistas, vemos que de diversas formas se sigue marginando la profesión y dando una imagen devaluada de las actividades que realizan las enfermeras, a pesar de la importancia social que se le reconoce a su labor (Garcia Banon, M. et al. 2004).

Florence Nightingale cambió el rol de las mujeres en la enfermería, al convertirlas de seguidoras del ejército en profesionales de la atención y del cuidado de enfermos y heridos, ya que antes de esa época, sólo a los hombres se les permitía brindar esos cuidados, ya que se suponía que cualquier mujer que adoptase esa profesión "innoble" sería, además prostituta (Cohen H.1988).

Se espera siempre que las enfermeras demuestren rasgos que se consideran "femeninos", como la cordialidad, la generosidad y el servicio. Uno de los estereotipos de la imagen social de la enfermera es el de madre/monja/servidora dispuesta a prestar los cuidados que sean precisos.

De hecho estos rasgos están tan incorporados en la mentalidad popular, que en algunos países se pone en tela de juicio la masculinidad de cualquier enfermero varón (Harding T. 2007), ya que los hombres enfermeros que realizan una profesión de mujeres, tienen que ser necesariamente afeminados, aunque como es característico de los estereotipos evidentemente no sea cierto, es la misma circunstancia que persigue a los peluqueros y modistos, sobre todo si son de mujeres, a los que este estereotipo los persigue. 
Los manuales para la enfermería española editados en nuestro país entre 1955 y 1976 contribuyeron a desarrollar estrategias de poder de carácter fundamentalmente disciplinario encaminados a modelar conductas de sumisión y dependencia que propició la constitución de una profesión centrada en la tarea y las virtudes morales y no en habilidades analíticas y conceptuales. En la actualidad a pesar de que han pasado treinta años algunos de estos elementos permanecen aún presentes en la base de las prácticas, relaciones profesionales, políticas sanitarias y las imágenes sociales (Miro Bonet et al. 2008) que se trasmiten de la enfermería y las enfermeras. En la construcción de los estereotipos que hay acerca de la profesión enfermera han influido el sexo, femenino y su propia historia (Rubio Pilarte J. 2006).

La aprobación de la Ley de Ordenación de Profesiones Sanitarias (LOPS) en 2003, confirmando la Enfermería, a todos los efectos legales, con un campo de actuación propio y con su propia metodología, tampoco nos ha quitado la imagen de subordinación total al colectivo médico, con poca autonomía profesional y con escasas o nulas posibilidades de progresar en los medios de comunicación.

Para resumir la visión que tiene la sociedad o una parte de ella sobre la enfermeras oscila entre una imagen idealizada considerándolas "ángeles al servicio de los hombres" como se denominaban en algunas Escuelas de la época, hasta como mujeres de "vida ligera" ya que no podemos olvidar que las enfermeras ocupan también un lugar preeminente en las películas pornográficas.

En nuestro entorno, los estudios sobre estereotipos de género y enfermería son escasos, aunque diversos autores han reflexionado sobre ello Colpo et al (2006), Siles González, 1998), Alberdi (1998) y Alberdi y Cuixart (2005) sin olvidar el brillante trabajo de Margalida Miró y Gloria Gallego, (2006).

Annette M. Links, (2004, 1993), realizó unos estudios sobre las actitudes de género y estereotipos en relación con enfermería entre los estudiantes recién ingresados en una Escuela. El trabajo estaba basado en un cuestionario, que era el resultado de un estudio anterior, en él se evaluaban las actitudes y estereotipos y su relación con las variables de edad, género y experiencia previa con la enfermería.

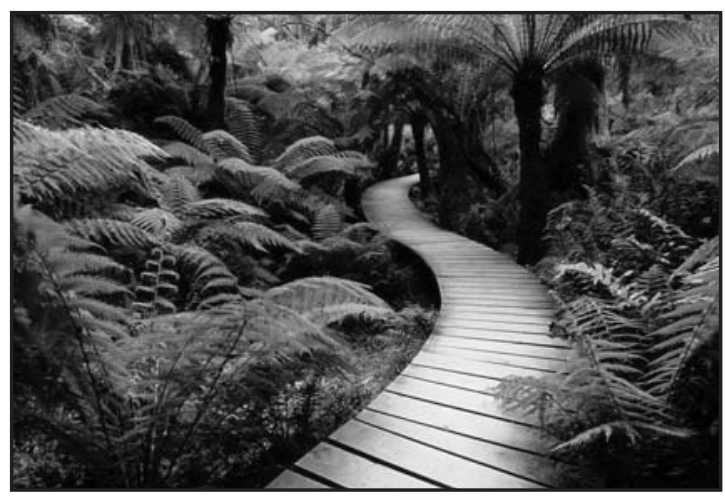

En nuestra búsqueda bibliográfica no encontramos estudios similares, realizados en nuestro entorno, o en el mundo de habla hispana, por lo que nos planteamos conocer posibles concordancias o diferencias entre nuestros resultados y los hallados del estudio original.

\section{JUSTIFICACIÓN}

Un estudio sobre las percepciones sobre la enfermería que presentan los estudiantes, puede contribuir a conocer los estereotipos sobre la profesión, y de manera muy especial los estereotipos de género que se proyectan en el ámbito de la enfermería, con el fin de facilitar el posicionamiento y las herramientas necesarias que los docentes de las escuelas de Enfermería deberán utilizar para intentar modificarlos.

\section{HIPÓTESIS}

La formación universitaria de las enfermeras no influye en el cambio de los estereotipos de género, que presentan los estudiantes de Enfermería al inicio de su formación.

\section{OBJETIVOS GENERALES}

Describir las actitudes de los estudiantes de Enfermería ante una imagen estereotipada del profesional enfermero.

Valorar si hay evolución en la percepción de los estereotipos de género de enfermería de los estudiantes, a lo largo de su formación universitaria.

\section{OBJETIVOS ESPECÍFICOS}

- Describir las actitudes y percepción de los estudiantes de primer curso, recién ingresados en los estudios en función de: 
- Sexo (masculino y femenino)

- Elección de estudios (primera opción o segundas opciones)

- Procedencia (estudios previos)

- Escuela

- Describir las actitudes y percepción de los estudiantes al finalizar el tercer curso en función de:

- Sexo (masculino y femenino)

- Elección de estudios (primera opción o segundas opciones)

- Procedencia (estudios previos)

- Escuela

\section{SUJETOS Y MÉTODO}

Nuestro trabajo lo planteamos desde dos mediciones: la primera, la realizaríamos al ingresar los estudiantes en la Escuela, y compararíamos nuestros resultados con los del trabajo original de Links y una segunda que efectuaríamos al acabar estos mismos alumnos los estudios antes de dejar la Escuela, y en el que compararíamos los resultados con los obtenidos en la primera medición y veríamos si se habían producido modificaciones en cuanto a su percepción sobre estereotipos de genero.

Se trata de un estudio observacional y diacrónico.

Se realizó una encuesta. (Ver anexo I) estructurada a una población compuesta por un total de 440 sujetos, formada por todos los alumnos de primer curso en tres escuelas de enfermería, pertenecientes a dos Universidades privadas y una pública, en los primeros días de su ingreso en la Escuela y antes de que tuvieran contacto directo con el medio sanitario como estudiantes de Enfermería durante el curso 2006/07.

Al finalizar el tercer curso 2008/09 se volvió a pasar el mismo cuestionario a un total de 307 alumnos de las tres Escuelas de Enfermería antes mencionadas.

Los datos de la tabla 1 muestran los tamaños muestrales de las encuestas realizadas en cada escuela, en los momentos antes (primer curso), y después (tercer curso). Se observa una diferencia importante en el número de alumnos encuestados en la escuela primera (una de las privadas). Esto puede suponer un cierto sesgo en los resultados obtenidos, aunque teniendo en cuenta los tamaños muestrales grandes, podemos considerar que los resultados arrojan indicios importantes sobre la manera de pensar de los estudiantes de enfermaría.

El cuestionario fue traducido del trabajo original del inglés por un traductor cualificado. Su grado de comprensibilidad se evaluó mediante un estudio piloto en el que participaron 20 sujetos de forma voluntaria. Se trata de un cuestionario con 12 ítems que sigue un esquema tipo Likert, con respuestas que van del 1 al 5 , siendo la puntuación 1 el completo desacuerdo y el 5 el máximo acuerdo. La puntuación 3 indica indiferencia.

\section{El cuestionario incluía:}

- Cuatro ítems sobre estereotipos de género.

- Dos ítems sobre enfermería como profesión femenina.

- Tres ítems sobre estereotipos de enfermería femeninos.

- Un ítem sobre estereotipos de la enfermería masculina.

- Un ítem sobre el uniforme de las enfermeras y su influencia en los estereotipos.

- Un ítem sobre discriminación de género en la enfermería.

Además se recogieron las variables demográficas: edad y género, la procedencia del alumnos: selectividad, Formación profesional u otra diplomatura; si Enfermería era su primera o segunda opción y por último si había tenido o no experiencia previa con Enfermería.

El cuestionario empleado difirió del original en inglés, en el que la pregunta relacionada con el uniforme que llevan los enfermeros y las enfermeras, que es diferente en Inglaterra, se tuvo que obviar dado que en nuestro país, el uniforme es igual para ambos sexos (bata y/o pijama) en casi todos los casos; esta pregunta fue sustituida por otra con la que los autores pensamos que pudiera sustituirla y relacionada con el uniforme que durante años han llevado las enfermeras españolas.

Asimismo se incluyó la procedencia de los estudiantes, en cuanto a su ingreso en la Universidad, ya que en nuestro país puede darse por varias vías y nos parecía interesante conocer si estas experiencias previas influían en la percepción de los estereotipos 
Los datos recogidos se introdujeron en una base de datos en formato Xbase y para el análisis estadístico se utilizó el programa SPSS 15.0. Las pruebas estadísticas utilizadas han sido las correspondientes al tipo de variables que se han estudiado en la muestra. En concreto, se han comparado las medias de las respuestas en los casos antes-después, sexo, y escuela. Para las primeras se ha usado la prueba t. En este caso la hipótesis de normalidad no es crítica, ya que los tamaños muestrales son suficientemente grandes. Para las medias por escuelas, se ha usado la prueba ANOVA, cuya hipótesis nula, es que por escuelas, los alumnos puntúan igual en promedio. En caso de rechazo pasa a analizar los motivos de ello y se usa el test de HSD de Tukey, que permite agrupar las escueles según la similitud de respuestas (en promedio). Se elige como nivel de significación global para todas las pruebas a $\geq 0.05$.

Puesto que la muestra no es aleatoria, la extrapolación de los datos obtenidos a la población debe ser tomada con mucha cautela. Pero dados los tamaños muestrales, el hecho de que hay suficiente pluralidad en los tipos de escuela (privada, pública), los resultados obtenidos pueden ser considerados como indicio de lo que pasa en la población de estudiantes de enfermería de nuestra comunidad, pudiendo ser extrapolables al resto de población estudiantil del resto del Estado.

\section{RESULTADOS}

El análisis exploratorio de datos dio los siguientes resultados:

Las características demográficas de la población son:

Mujeres 615 y hombres 124, concordando con la población de estudiantes de enfermería en general.

En cuanto al número de encuestados por Escuela se muestra en la tabla 2 siguiente:

En cuanto a su procedencia el $68 \%$ habían accedido a la Escuela por selectividad, el 23\% procedía de la Formación Profesional (FP) y 49\% de otra diplomatura o licenciatura.

El grupo de edad más frecuente fue el comprendido entre los 18 y $23(71 \%)$ años, seguido por el de 25-30 años con un 12\%, siendo el mayor de 31 años un 11\%. Dado que la mayoría de los encuestados esta entre los 18-25 años, no conside- ramos interesante introducir la variable edad como variante discriminatoria en las opiniones de los estudiantes.

La elección de estudios fue fundamentalmente primaria ya que el $69 \%$ procedían de la selectividad, el resto de los grupos se distribuían entre los procedentes de FP 24.2\% y el $6.7 \%$ que habían accedido por tener otra diplomatura o licenciatura

La tabla 3 resume las respuestas globales de los encuestados frente a los 12 ítems del cuestionario.

Hay un mayoritario acuerdo en considerar a las mujeres "más cariñosas que los hombres", en el resto de los ítems hay indiferencia o tendencia al desacuerdo

En la $2^{\mathrm{a}}$ medición se considera a los hombres más independientes (p-valor: ,000) y más inteligentes (p-valor: ,000), además de opinar que se identifica a las enfermeras con la cofia y la minifalda (p-valor: ,009)

En relación al sexo, observamos que las mujeres se consideran a sí mismas más cariñosas ( $\mathrm{p}$ valor: ,000), mejores enfermeras ( $p$-valor: ,000), con menor capacidad de liderazgo (p-valor: ,000), menos independientes (p-valor: ,000) y menos inteligentes ( $\mathrm{p}$-valor: ,000) y con menores posibilidades de promoción ( $\mathrm{p}$-valor: ,002). Por el contrario los hombres se consideran a si mismos más lideres (p-valor: ,002), más independientes ( $p$ valor: ,000), más inteligentes ( $\mathrm{p}$-valor: ,000) y con mayores posibilidades de promoción ( $\mathrm{p}$-valor: ,000) además de considerar que se identifica a las enfermeras por la cofia y minifalda (p-valor: ,019. Que las mujeres son más cariñosas que los hombres (p-valor: ,000) y que son mejores enfermeras (p: ,000).

Cuando comparamos las tres Escuelas mediante ANOVA, alcanzan niveles de significación estadística los ítems siguientes:

Enfermeras mayores duras y mandonas ( $\mathrm{p}$ valor: ,002), siendo la Escuela 3 la que esta más en desacuerdo; "las enfermeras jóvenes se ven como objetos sexuales" (p-valor:,000, )también es la Escuela 3 la que más bajo puntúa. Enfermeras secretarias de los médicos (p-valor: ,003), asimismo escuela 3 junto con el ítem mujeres mejores enfermeras ( $\mathrm{p}$-valor: ,031 que la escuela 3 puntúa más bajo.

En cuanto al ítem "enfermería profesión femenina" (p-valor: ,000), es la Escuela 2 la que está 
más de acuerdo con esa afirmación; por el contrario en el ítem "hombres más inteligentes" ( $p$-valor: ,000), es la escuela 1 la que esta más de acuerdo, por el contrario esta misma escuela en el ítem "los hombres son más independientes" (p-valor: ,000) está más en desacuerdo que las otras dos escuelas. Puntúan de manera similar; "mujeres más cariñosas" (p-valor:,000). Siendo la escuela 3 la que está más en desacuerdo; "las enfermeras se asocian con la cofia y minifalda" (p-valor: ,000 ) son las escuelas 1 y 3 las que puntúan más bajo y la 2 más alto. Las tres escuelas arrojan una puntuación similar al ítem "los enfermeros tienen más posibilidades de promoción", no alcanzando el nivel de significación estadística

\section{ANÁLISIS DE CONGLOMERADOS (análisis conjunto de todas las variables)}

El objetivo de esta técnica es agrupar las variables en conglomerados o clusters, de manera que las variables semejantes estén en el mismo grupo, y éstos sean entre sí lo más diferentes posibles. La distancia entre variables es la distancia la euclídea al cuadrado, y la forma de agrupar variables en clusters es la vinculación intra-grupos. El gráfico que representa la relación entre variables se llama dendograma, y visualiza la relación entre las variables de manera aquellas más cercanas quedan en el mismo grupo.

Esta técnica tiene en este caso, el objetivo de comprobar la coherencia de las respuestas de los encuestados. Cabe esperar que aquellas preguntas que están relacionadas por su respuesta, están en el mismo grupo. En caso de no ser así, cabría pensar que los encuestados no han respondido coherentemente a la encuesta. En este caso usamos esta técnica como método de validación de la encuesta.

Se observan los siguientes clústers (cuatro en total) agrupados en: $1^{\text {er }}$ grupo (1 y 9), $2^{\circ}(7,8$ y $11), 3^{\circ}(3,4,5,6,10$ y 12$), 4^{\circ}$ (2) (Figura 1$)$.

El $1^{\circ}$ aunque parezca contradictorio o antagónico puede estar condicionado por la potencia de los dos estereotipos identificados (cariñosas y enfermeras mayores duras y mandonas respectivamente) que están muy arraigados en el ámbito cultural y social de nuestro medio.

El $2^{\circ}$ agrupa los estereotipos de género/profesión que aún hoy en día se mantienen vigentes y que tienen una importante carga de relación con aspectos como la obediencia, la sumisión o la docilidad.

El $3^{\circ}$ agrupa todos los estereotipos que se pueden dar en relación con la enfermería en el ámbito laboral.

Por último el ítem 2 queda aislado no pudiéndose establecer relación alguna con el resto de ítems, lo que puede ser interpretado como un estereotipo universal e independiente de cualquier otro.

Conclusión: la agrupación de variables se realiza según lo esperado. Se observa que las semejanzas entre las variables, según su respuesta, conducen a agrupar las variables en el mismo cluster. Debemos concluir que los encuestados responden coherentemente a la encuesta.

\section{DISCUSIÓN}

Los resultados de este estudio aportan perspectivas interesantes sobre las percepciones de los estereotipos de género y enfermería, sostenidas por los estudiantes recién ingresados en las Escuelas donde se realizaron el estudio. Estereotipos que persisten y no se eliminan durante el proceso de formación de las futuras enfermeras, por lo que la hipótesis del presente trabajo se confirma

En líneas generales los resultados sugieren evidencia en la persistencia de imágenes de enfermeras de acuerdo con los estereotipos femeninos más obsoletos: ángeles, vírgenes, objetos sexuales, putillas o autoritarias, coincidiendo con los estereotipos comunes a las mujeres, independientemente de su profesión, tal como se recoge en los estudios de Muff, J. (1988) Kalisch, BJ et al. (1982) y Salvage, J. (1985 y 1987).

El grupo de edad más numeroso fue el de 19 24 años (71\%), que es el coincidente con el final de la educación secundaria y el acceso a la universidad en nuestro país y similar a la primera medición de Links realizado por Jinks, A. (1993).

Existe un mayoritario acuerdo en todas las respuestas con respecto al ítem "las mujeres son más cariñosas que los hombres" coincidente con el estudio de Jinks, A. (2004) además de estar asociada la idea al cuidado, estereotipo que se asigna a la mujer en las sociedades tradicionales y que supone además dedicación y entrega como elementos de mayor importancia que la preparación profesional, lo que coincide con los estudios de Cunningham, A. (1999), Berry, L. (2004), Martínez Riera, JR. (2003). 
Los resultados de nuestro estudio en relación a los ítems que hacen referencia a que "los hombres son más independientes y más inteligentes que las mujeres" coinciden con los obtenidos en el estudio de Jinks, A. (2004).

En cuanto a la asociación de la enfermera con la cofia y minifalda, no podemos establecer ningún tipo de asociación con el estudio de Jinks, A. (1993) u otros similares dado que este ítem es específico de este cuestionario y no se recoge de igual manera en los estudios consultados a nivel internacional. Sin embargo sí que coincide con los resultados de estudios en nuestro ámbito, como el de Burguete, MD. et al (2005) y Martínez Riera, JR. (2006).

La valoración de que las mujeres son más cariñosas que los hombres en nuestro estudio alcanza una mayor puntuación que en el de Jinks, A. (2004).

En cuanto al liderazgo, independencia e inteligencia de los hombres en relación con las mujeres nuestros resultados coinciden globalmente con los del estudio de Jinks, A. (2004), aunque en nuestro estudio al estar separados por sexo encontramos diferencias en los hallazgos obtenidos en función de esta variable. Siendo los hombres quienes tienen hacía sí mismos una mayor consideración y las mujeres menor hacia ellas mismas.

En el estudio de referencia de Jinks, A. (2004), las oportunidades de promoción entre los enfermeros muestra una media superior que en nuestro estudio.

La asociación entre ser enfermero y ser afeminado tiene una clara diferencia entre el estudio de Jinks, A. (2004), en el que si que establecen dicha asociación en mucha mayor proporción que en nuestro estudio. Además cabe destacar que no existen diferencias en esta valoración en función del sexo.

\section{CONCLUSIONES}

El principal objetivo de este estudio ha sido el no prejuzgar las imágenes que los estudiantes de enfermería tienen de la enfermería en general y de las enfermeras en particular.

En sentido identificamos como principales conclusiones:

A pesar del evidente avance en la profesionalización y desarrollo disciplinar enfermero, se sigue manteniendo la evidencia de lo innato de los comportamientos asociados al género. Persistiendo las imágenes más reaccionarias comunes a los estereotipos asociados a las mujeres y por extensión a las enfermeras.

Los estereotipos de género se identifican tanto en alumnos de Escuelas adscritas a Universidades públicas como privadas, lo que pone manifiesto que dichos estereotipos no obedecen a una cuestión de pertenencia a unas $\mathrm{u}$ otras.

Los hombres tienen mayor valoración de sí mismos con relación a los valores culturalmente asociados al género masculino y las mujeres refuerzan esta apreciación.

Las valoraciones no sufren cambios sustanciales en función del tiempo transcurrido desde el principio de la formación a la finalización de la misma.

Los currículos docentes de enfermería no facilitan los cambios necesarios en la identificación y fijación de estereotipos ligados al género y a la enfermería.

Existe la necesidad, de que los actuales programas educativos de enfermería incluyan de forma transversal apartados relacionados con estereotipos de género, la discriminación por género y el desarrollo de estereotipos de enfermería.

\section{BIBLIOGRAFÍA}

- Alberdi Castell, RM. (1998). La influencia del género en la evolución de la profesión enfermera en España Metas Enferm II(11):20-26

- Alberdi Castell, RM; Cuxart Ainaud, N. (2005). Cuidados, enfermeras y desarrollo profesional: Una reflexión sobre las bases del ejercicio profesional Rev. Presencia.

- Berry, L. (2004). Is image important? Nursing standard.;18(23):14-6.

- Burguete Ramos MD, Ávila Olivares JA, Velasco Laiseca J. (2005). La imagen pública de las enfermeras. Cómo ven la profesión los estudiantes de enfermería. Educare 21; 17[En línea] [fecha de acceso: 28 de abril de 2009]. URL disponible en: http://www.enfermeria21.com/educare/educare17/ensenando/ensenando1.htm

- CEP. (2005). La socialización diferencial y la autoeficacia capitulo 3. En Discriminación de género e igualdad de oportunidades. Manual. Madrid; p: 4.

- Cohen H. (1988). La enfermera y su identidad profesional. Barcelona Grijalbo. p 178.

- Colpo JC, Camargo, V. Simey A. (2006). La imagen de la enfermera como objeto sexual en las medias: un molesto a la profesión Enfermería.. 11(1):67-72

- Cunningham, A. (1999). Nursing stereotypes. Nursing standard, 13(45):46-7.

- Garcia Banon, AM. Sainz Otero, A. Botella Rodriguez, M. (2004). La enfermería vista desde el género. Index Enferm. [online]. vol. 13, no. 46 [citado 2009-01-09], pp. 45-48. 
- Harding T. (2007). The construction of men who are nurses s gay. Journal of Avanced Nursing, 60(6): 636-44

- http://www.enfermeria21.com/educare/Generalitats/componentes/articulos/enlace_articulo.php? $\mathrm{Mg}==\& \& \mathrm{MjU}=\& \mathrm{MTc} 1 \mathrm{Ng}$

- Jinks AM. (1993). Study of attitudes to gender and nursing stereotypes in newly recruited student nurses. Nurse Educ Today. 13(4):287-94.

- Jinks AM. (2004). Angel, handmaiden, battleaxe or whore? A study which examines changes in newly recruited student nurses' attitudes to gender and nursing stereotypes. Nurse Educ Today. 24(2):121-7.

- Kalisch BJ, Kalisch PA, Mchugh ML. (1982). The nurse as a sex object in motion pictures, 1930 to 1980 . Res Nurs Health. 5(3):147-54.

- Levi-Strauss C. (1961). Antropología estructural. Capitulo X, la eficacia simbólica Endebo. Buenos Aires.

- Martínez Riera, JR. (2003). Cuidados informales en España. Problemas de desigualdad. Revista Administración Sanitaria (RAS), 1 (2): 275 - 288

- Martínez Riera, JR. Cibanal Juan, L. (2006). Enfermería: ¿qué imagen tienen de ella los alumnos? Educare 21; 26 [En línea] [fecha de acceso: 28 de abril de 2009]. URL disponible en:

- Miro Bonet, M. Gastaldo, D. Gallego-Camillero, G. (2006). El discurso feminista en la construcción de la identidad profesio- nal de las enfermeras en España (1956-1976). En Los feminismos como herramientas de cambio social / coord. Por Esperanza Bosch Fiol, Victoria Aurora Ferrer Pérez, Capilla Navarro Guzmán, Vol. 1, (Mujeres tejiendo redes históricas, desarrollos en el espacio público y estudios de las mujeres), Págs. 247-261. Universidad de la Rioja

- Miro Bonet, M. Gastaldo, D. Gallego-Camillero, G. (2008). ¿Por qué somos como somos? Discursos y relaciones de poder en la constitución de la identidad profesional de las enfermeras en España (1956- 1976). Enfermería Clínica;, 18(1) pp.24-32.

- Mompart, MP. (1994) Administración de los servicios de Enfermería Masson-Salvat p 98

- Muff J (1988). Meeting the goddesses: exploring the positive feminine in nursing stereotypes. Imprint. 35(4):42-

- Rubio Pilarte J. (2006). ¡Por favor, una enfermera! Emferm Clin.16(4):169-71

- Salvage J. (1987). Nurses, gender and sexuality. Heinemann, Oxford.

- Salvage J.: (1985). The politics of nursing. Heinemann, Oxford.

- Siles González, J. et al. (1998). La enfermería en el cine: imagen durante la guerra civil española Rev ROL Enferm XXI(244):25-31

Tabla 1 Contingencia Momento * Escuela

\begin{tabular}{|ll|c|c|c|c|}
\hline & \multicolumn{3}{|c|}{ Escuela } & \multirow{2}{*}{ Total } \\
\cline { 3 - 5 } & & $\mathbf{1}^{\mathbf{a}}$ escuela & $\mathbf{2}^{\mathbf{a}}$ escuela & $\mathbf{3}^{\mathbf{a}}$ escuela & \\
\hline Momento & Antes & 234 & 131 & 73 & 438 \\
& Después & 118 & 129 & 60 & 307 \\
& & 352 & 260 & 133 & 745 \\
\hline
\end{tabular}

\begin{tabular}{|ll|c|c|c|c|}
\hline \multicolumn{6}{|c|}{ Tabla 2. Procedencia de Escuela } \\
\hline & & Frecuencia & Porcentaje & $\begin{array}{c}\text { Porcentaje } \\
\text { válido }\end{array}$ & $\begin{array}{c}\text { Porcentaje } \\
\text { acumulado }\end{array}$ \\
\hline Válidos & $1^{\circ}$ & 352 & 47,1 & 47,2 & 47,2 \\
& $2^{\circ}$ & 260 & 34,8 & 34,9 & 82,1 \\
& $3^{\circ}$ & 133 & 17,8 & 17,9 & 100,0 \\
& Total & 745 & 99,7 & 100,0 & \\
Perdidos & Sistema & 2 & 3 & & \\
Total & & 747 & 100,0 & & \\
\hline
\end{tabular}

Tabla 3. Respuestas globales del cuestionario

\begin{tabular}{|l|r|r|r|}
\hline Items & N & Media & Desv. típ. \\
\hline Mujeres más cariñosas & 746 & 3,36 & 1,133 \\
Hombres más independientes & 743 & 2,27 & 1,082 \\
Hombres más inteligentes & 743 & 2,04 & 1,053 \\
Hombres más lideres & 741 & 1,96 & 0,970 \\
Enf Profesión femenina & 739 & 2,34 & 1,214 \\
Mujeres mejor enfermeras & 744 & 2,15 & 0,967 \\
Enf secretarias médicos & 741 & 2,30 & 1,251 \\
Jóvenes objetos sexuales & 744 & 2,12 & 1,143 \\
Mayores mandonas & 741 & 2,86 & 1,098 \\
Enfermeros afeminados & 741 & 1,58 & 0,791 \\
Cofia y minifalda & 744 & 2,35 & 1,225 \\
Enfermeros promoción & 743 & 2,25 & 1,012 \\
\hline
\end{tabular}


Dendrogram using Average Linkage (Between Groups)

Rescaled Distance Cluster Combine

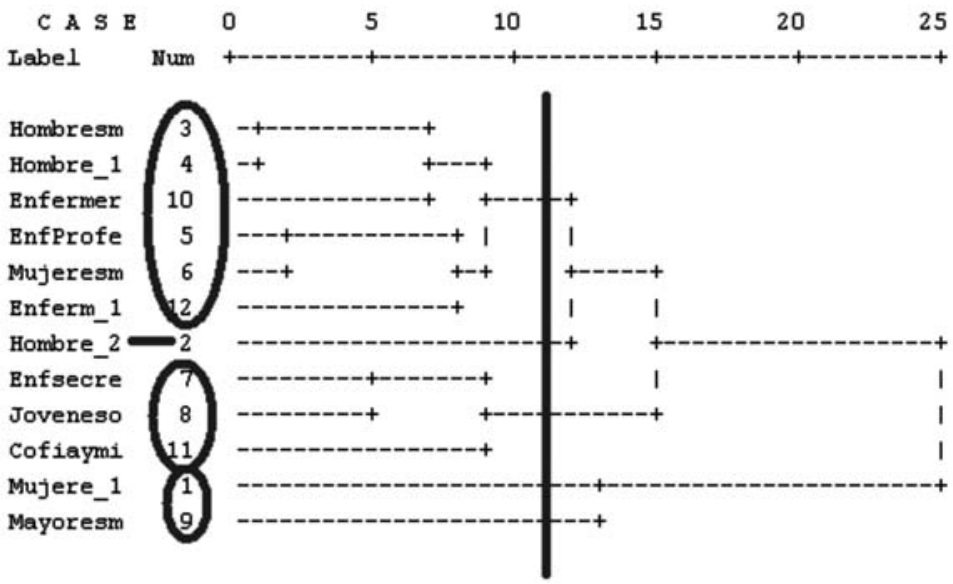

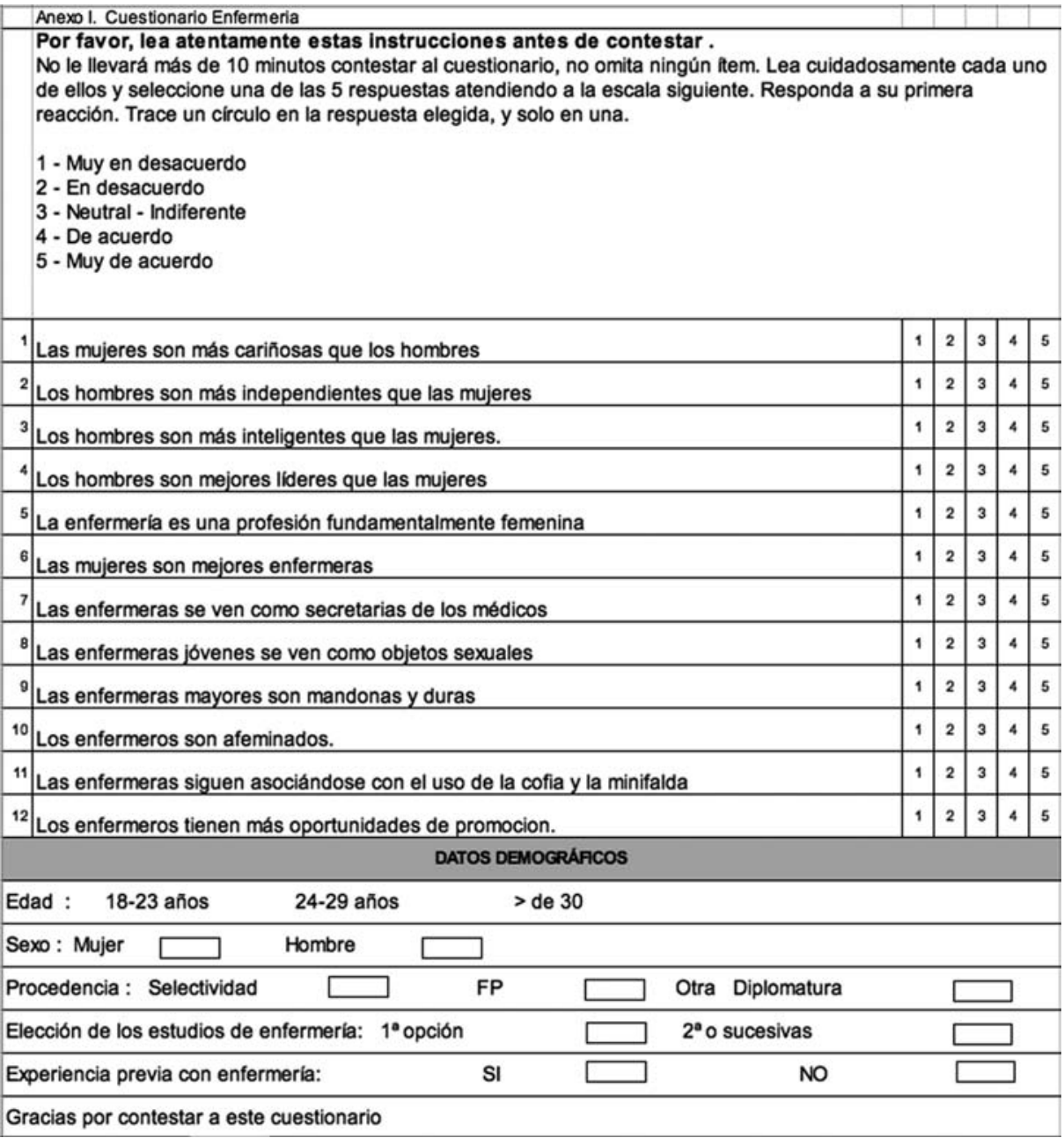

